\title{
1. Innovation policy in multi-tier Europe: introduction
}

\section{Anna Kaderabkova and Slavo Radosevic}

This volume is the result of an expert group assembled under the auspices of the Czech European Union (EU) presidency in 2009. The group was mandated to explore innovation policy issues in the EU in light of the increased divergence of the EU27 and the realization that these differences require different policy approaches. The enlarged EU27 represents a new architecture of countries that can no longer be defined by a simple EastWest divide, with most innovation indicators suggesting the existence of a multi-tier Europe in terms of innovation capacity (Radosevic, 2004; EC, 2009; also see Chapter 8 in this volume, Figure 8.1). It would be unrealistic, therefore, to expect that similar policies and indicators could be used to gauge and benchmark the innovation performance of these countries. Rather than a criterion of frontier technology, policies need to encompass sets of criteria relevant to the technology profiles of individual countries. This calls for a perspective that takes account of the cross-country heterogeneity of existing national systems of innovation (NSI) and the technology positions of countries in relation to the technology frontier. A countryspecific approach should be combined with sector-specific approaches, which highlight the diversity of technology modes across industry. This understanding of innovation and growth in Europe is not compatible with current policy practice. The main tenets of EU-level innovation policy were conceived before accession of the new member states (NMS) and were based on generic and horizontally-oriented policies applied in a uniform manner across a large number of countries. These would seem to be insufficient since they involve long gestation and do not cater to the specific requirements of groups of countries based on their different distance from technological frontier countries.

This thinking is based on the logic underpinning (neo)Schumpeterian growth theory (Aghion and Howitt, 1998), the perspective used in this volume to explore innovation policy issues. (Neo)Schumpeterian theory implies that policies and institutions can have long-lasting effects on economic growth, and that they should differ depending on the position 
of a country in relation to the technology frontier. This book provides a unique application of the Schumpeterian innovation policy perspective in the context of the countries of Central and Eastern Europe (CEE). It is an example of the kind of applied work formally developed by Philippe Aghion, a contributor to this volume, and by Richard Nelson, Chris Freeman, Carlota Perez, Luc Soete, Bengt-Ake Lundvall, Franco Malerba and colleagues, in a range of neo-Schumpeterian 'appreciative theorizing' type contributions. What distinguishes this book is that it employs this perspective explicitly and systematically, in the context of the EU, and EU new member CEE states in particular. The approach is applied on several dimensions (sectoral, demand, foreign direct investment (FDI), finance, education and innovation policy proper), combining empirical and conceptual analysis.

The focus on EU and the NMS in this book is logical given the multitier European context in which CEE countries are operating as peripheral economies in terms of technology generation. It stems also from an understanding that the same policies may not be effective for countries at very different distances from the world technology frontier. As Aghion et al. (2006: 13) point out, growth policy requires that the 'characteristics of the country or sector such as its degree of technological development or the extent of financial constraints, the nature of slow moving institutions in that particular country or sector, be taken into account'.

Projected growth in the EU27 is based on innovation and knowledge which translates into different sets of requirements for different countries. Nevertheless, in all cases growth requires complementary policies, that is, innovation policy and structural reform that is coherent with competition, higher education, labour market flexibility and financial market development policies, all of which must be tailored to the individual countries of the EU27. For example, an exclusive focus on entry and exit barriers in new technology intensive sectors is relevant for industries and countries close to the technology frontier, but perhaps not for those that are farther away. As has been demonstrated elsewhere (Arundel et al., 2008), there has been a general failure in policy to support non-research and development (R\&D) innovators to upgrade their innovative capabilities. This applies particularly to CEE, where the share of $R \& D$ innovators is disproportionately high, but policy is focused on support for R\&D innovation. There also needs to be good coherence between structural and macroeconomic policies throughout the business cycle (Aghion, 2006). This is currently lacking in Europe, and CEE countries are increasingly suffering the effects of unaligned policies. As Aghion (2006) argues, countercyclical budgetary policies are more growth-enhancing in countries with less developed financial systems and, thus, their absence in CEE, whose financial development is poor, is very detrimental. 
The general focus of this volume is on innovation policy, but within a broadly defined framework of science, technology, innovation and growth (STIG) systems (Aghion et al., 2006). Specifically, we examine the (in) capacity of CEE to play a more important role in the knowledge-based competitiveness of the EU. We explore whether it is possible to bolster this capacity with innovation/technology/industry-specific policies, and discuss the changes that would be needed at EU and individual country levels to remove sector (industry)-specific obstacles to greater competitiveness based on innovation. We analyse these policies from the perspective of growth, which makes their investigation informative for education, labour market and competition policy.

In countries and industries that are far from the technology frontier, technology transfer and non-R\&D-based innovation activities are important drivers of innovation. In these countries, increasing levels of technology transfer and absorptive capacity through $R \& D$ and training should be a priority. In more advanced countries which rely on knowledge-intensive foreign imports, innovation policy should support a gradual move from the acquisition to the production of knowledge. Countries at or close to the technology frontier should foster R\&D in companies and universities. In sum, innovation policy needs to be country-specific in the sense of tackling those aspects of national innovation capacity that are major bottlenecks.

The contributors to this volume are critical of EU-wide policy approaches that ignore individual country needs. The use of a single yardstick, whether policy metrics such as the European Innovation Scoreboard, methods such as the open method of coordination, or imposed policy objectives such as the 3 per cent, take no account of these differences. Policies for countries where growth is based on technology absorption need to be different from policies applied to countries where growth is based on R\&D and technology frontier innovation.

Nevertheless, there are some innovation challenges that apply to all countries and sectors such as shortages of skilled human resources and financing for business R\&D. The policy mix needs to be broad-based and to take account of 'framework conditions'. Only specific or only general policies will not be effective and are not substitutes for one another.

Such issues are the core of this volume and the basis of its coherence. We believe it will be essential reading for those interested in the issue of innovation policy in Europe.

Chapter 2 by Slavo Radosevic provides an analytical introduction to and context for the succeeding chapters. It positions innovation and innovation policy issues in CEE countries within the enlarged EU, and draws comparisons with the developed EU. It outlines the rationale for 
developing a new policy approach, endorsed by the other contributors to this volume, which takes account of technological and developmental differences across countries. It outlines some policy implications of a specific country/country group approach which are developed in the following chapters.

Chapter 3 by Philippe Aghion, Heike Harmgart and Natalia Weisshaar introduces a general framework for designing medium term growthenhancing policies through a focus on specific policies relating to competition, education and finance. It reviews the growth experiences of the European transition countries and argues that general and non-sectorspecific government intervention can substantially increase long-term growth prospects in these countries. While specific sectors might receive greater benefits from specific policy measures, this chapter emphasizes the contribution of overarching growth-enhancing policies. It focuses on two areas where policy could be particularly effective, namely competition and education quality. First, if transition countries are to achieve - and sustain - higher long-run growth rates, they will need to support competition by continuing to remove entry and trade barriers and by strengthening - and in some cases setting up - competition agencies. This applies particularly to the Commonwealth of Independent States (CIS), resource-rich countries. Second, the transition countries as a group need to invest more in the quality of primary and secondary education, which, in turn, implies that they need to invest more in tertiary, especially undergraduate, education to produce better quality teachers, and in the evaluation and monitoring of their education systems. Again, somewhat paradoxically, it is the resource-rich CIS countries that are suffering most from insufficient investment in education and problems related to the quality of their education services. This chapter argues finally that there may be scope for macroeconomic policies to boost spending in these key areas. In the area of education, in particular, the role of the private sector in overcoming skills mismatches will benefit from more intensive financial intermediation and a reduction in the barriers to finance.

Chapter 4 by Andreas Reinstaller and Fabian Unterlass explores sectoral innovation policy and its relevance and implications for the NMS from CEE. First, they establish the extent to which industry specialization affects the assessment of national innovation capability. They develop a country classification based on the technological profiles of EU countries and discuss the construction of meaningful industry classifications, based on the existing literature. The aim is to reduce the heterogeneity of firm innovation behaviour across industries and countries to a few salient types, enabling meaningful policy conclusions. Second, the authors analyse how industries differ in terms of their innovation strategies and 
how they exploit innovation opportunities, among the country groups identified in the first part of the chapter. The authors conclude with a discussion of how a better understanding of national specialization profiles and sectoral innovation modes could contribute to the design of policy mixes that would foster innovation, competitiveness and growth.

Chapter 5 by Alasdair Reid analyses the extent to which innovation policies in the CEE NMS reflect their individual industry and technology conditions and levels. This chapter examines the challenges related to designing innovation policies tailored to these states. It discusses the importance of types of 'system failure' in the NSI of the CEE countries and how they are being addressed by national policy; it reviews the innovation policy mix, including the role of EU Structural Funds, and its correspondence with the system failures identified. It argues in particular that CEE countries have specific innovation strengths and weaknesses, which call for the development of customized policies and not the blinkered application of a 'Europeanized' policy approach. The policy mix required for the CEE countries differs from policies appropriate for the 'average' EU25; in a number of cases the focus must be on resolving individual issues related to the stage of innovation (for example investment-driven approach to research, technology, development and innovation policy via technology acquisition by small and medium sized enterprises or promotion of the research infrastructure), tackling explicit bottlenecks in the NSI (for example doctoral studies in science and engineering, low levels of capabilities and spending on R\&D by domestic enterprises). Reid concludes that there is a need to widen the scope of innovation policy, to exploit linkages with other policies aimed at education and training, rather than trying simply to remedy the perceived underinvestment in business R\&D.

Chapter 6 by Rajneesh Narula explores the policy options for the integration of FDI and NSI, drawing on experience from around the world, but with a particular focus on EU NMS. He argues that the promotion of innovation activities by multinational enterprises (MNE) requires a somewhat different approach from the promotion of general valueadding activities. MNE innovative activities are increasingly fragmented across different locations to exploit particular aspects of different systems. Narula makes the distinction between two types of MNE R\&D. Demanddriven R\&D is activity undertaken to adapt existing products and services to local needs. Supply-side R\&D is innovation conducted in independent, knowledge-intensive, R\&D facilities and implies greater dependence on domestic knowledge sources and infrastructures. The two types of R\&D also imply different technology and innovation policy options and require a focus on scope and competence at the MNE subsidiary level. Approaches that focus on FDI flows as aggregates are flawed, since 
knowledge exchange and innovation are establishment-level phenomena. The different focus advocated in this chapter requires the introduction of an MNE policy to link FDI and industrial policy. CEE NMS should focus on attracting and fostering demand-driven MNE R\&D activities. Governments should reduce the emphasis on cost and increase the focus on specialized, location-bound knowledge assets, setting up programmes that will foster demand-oriented upgrading of public R\&D and human capital.

Chapter 7 by Jakob Edler examines demand and other conditions required for innovation and demand-based policies for innovation, in the context of EU CEE countries (CEECs). His argument is that institutional adaptations, and a policy mix that tackles bottlenecks in demand for innovation and supports the articulation of demand, can link modernization of the economy and public services to increased innovation in the EU CEEC economies, thereby contributing to an identifiable catching up process. Chapter 7 introduces the wider context of current demand-based innovation policies at EU level; it provides a conceptualization of demand-based innovation policy and introduces a typology of demand measures. Edler argues that our understanding of EU CEE countries' innovation capabilities falls short when it comes to capturing the demand side. He discusses alternative variables to map demand conditions in the EU CEE countries, linking this discussion to the challenges for policy. The overall finding from this chapter is that, in the CEE countries, efforts - both public and private - to articulate and support demand for innovation, are not keeping pace with attempts to boost the supply (of science and technology) and to compete in the international race for better supply conditions. The task is not so much about the construction of a technocratic machine able to pick winners and steer markets, but rather is about the innovation culture, and improving the responsiveness of the NSI to newly emerging needs and challenges.

Chapter 8 is co-authored by all the contributors to this volume and develops policy implications from their analyses. We adopt a perspective that takes account of the cross-country heterogeneity of existing NSI and their positioning in terms of innovation capacity, and that also recognizes the need for country-specific 'policy mixes' and complementarities between innovation policy, structural reforms and other policies. We discuss existing policies and the need for a rethinking of the EU innovation agenda. For example, even though EU policies allow for flexibility in implementing the Lisbon Agenda, many countries are focusing on improvements in a few R\&D-biased indicators (for example the Barcelona goal of 3 per cent of gross domestic product invested in $\mathrm{R} \& \mathrm{D}$ ) and are ignoring the need for policy measures to foster national innovation capability and 
competitiveness. The Lisbon Agenda and other goals create strong public and peer pressure for improvements in some areas, which, in the case of some countries, could be detrimental since formal R\&D is not the main innovation input for all industries and is less relevant during the process of catching up. This chapter highlights areas and actions that should be the focus of policy making in the EU, and especially the NMS. It discusses:

- the need to reconsider the balance between funding excellence and $\mathrm{R} \& \mathrm{D}$ relevance;

- the importance of improving education;

- provision of training;

- evaluating the use and design of Structural Funds to improve innovation capacity;

- institutional approaches for integrating FDI and innovation policy;

- spurring innovation through demand policies;

- investing in strategic intelligence and administrative capacity for more effective policy making.

The contributors to this volume constitute a team of people whose theoretical and empirical understanding of innovation policy issues in Europe is well recognized. The critical mass of these contributions and their clear focus on broad innovation policy in the enlarged EU makes this volume important reading for all those with an interest in these topics.

Innovation policy has become a mainstream activity. The innovation policy community has expanded much beyond the confines of government agencies, to encompass a broad array of consultancy firms, research groups, think tanks, students and enlightened public and business communities. We hope that this broad range of audiences will find this book interesting and informative and provide a better understanding of the issues of innovation and growth in the enlarged EU.

\section{REFERENCES}

Aghion, P. (2006), 'A primer on innovation and growth', Bruegel Policy Brief, 2006/06, Brussels: Bruegel.

Aghion, P. and P. Howitt (1998), Endogenous Growth, Cambridge, MA: MIT Press.

Aghion, P., P.A. David and D. Foray (2006), 'Linking policy research and practice in "STIG Systems": many obstacles, but some ways forward', SIEPR Discussion Paper No. 0609, Stanford, CA: Stanford Institute for Economic Policy Research.

Arundel, A., C. Bordoy and M. Kanerva (2008), 'Neglected innovators: how do 
innovative firms that do not perform $\mathrm{R} \& \mathrm{D}$ innovate? Results of an analysis of the Innobarometer 2007 survey No. 215, INNO-Metrics Thematic Paper, Maastricht: MERIT.

European Commission (EC) (2009), European Innovation Scoreboard, Luxembourg: European Commission.

Radosevic, S. (2004), 'A two-tier or multi-tier Europe? Assessing the innovation capacities of central and east European countries in the enlarged EU', Journal of Common Market Studies, 42(3), 641-66. 